\title{
Avaliação de diferentes técnicas de coloração histoquímica na identificação de oocistos de Cryptosporidium spp. em amostras de água e leite
}

\section{Evaluation of histochemical staining methods for identification of Cryptosporidium spp. oocysts in water and milk samples}

\author{
Erilane de Castro Lima, ${ }^{*}$ Valeska Shelda Pessoa de Melo, ${ }^{* *}$ Fábio Luiz da Cunha Brito, ${ }^{* * *}$ Leucio Câmara Alves, ${ }^{* * *}$ \\ Tânia Lúcia Montenegro Stamford*****
}

\begin{abstract}
Resumo
O Cryptosporidium, coccídio implicado como agente de infecções intestinais e transmitido pela rota fecal-oral, pode contaminar a água e alimentos, e através da veiculação hídrica e alimentar pode ser facilmente transmitido para um grande contingente da população. Métodos parasitológicos têm sido utilizados para a pesquisa de oocistos de Cryptosporidium em água e alimentos, porém vários fatores podem estar envolvidos no procedimento de coloração histoquímica de forma a influenciá-los nos aspectos quantitativos e qualitativos. Parâmetros como quantificação, morfologia, qualidade e durabilidade do esfregaço, influência da amostra e das substâncias de concentração foram avaliados com o objetivo de verificar as vantagens e desvantagens das técnicas Ziehl-Neelsen (ZN) e Koster (K) modificados na identificação de oocistos de Cryptosporidium spp. em amostras de água e leite, previamente concentradas com Sacarose, $\mathrm{NaCl}, \mathrm{MgSO}_{4} \mathrm{ZnSO}_{4}, \mathrm{AlSO}_{4}, \mathrm{NH}_{4} \mathrm{SO}_{4} 40 \%$ e $80 \%$. Não foi observada diferença estatística $(p<0,05)$ entre as técnicas em relação ao número de oocistos encontrados, porém verificou-se uma variação na superioridade da técnica $\mathrm{ZN}$ ou $\mathrm{K}$ de acordo com a amostra analisada, além de diferirem qualitativamente. Com relação à durabilidade do esfregaço as técnicas não apresentaram diferenças estatísticas. Quanto às substâncias utilizadas para a concentração dos oocistos na amostra, o $\mathrm{NH}_{4} \mathrm{SO}_{4}$ facilitou a identificação dos oocistos enquanto $0 \mathrm{AlSO}_{4}$ interferiu no processo de coloração. Conclui-se que a eficácia dos métodos de coloração histoquímica na identificação de oocistos de Cryptosporidium spp. depende da natureza da amostra e das substâncias empregadas para a sua concentração.
\end{abstract}

Palavras-chave: Cryptosporidium spp., Ziehl-Neelsen, Koster, água, leite.

\begin{abstract}
Cryptosporidium is coccidial protozoa responsible for intestinal diseases transmitted by the fecal oral route, and disseminated in the environment promote water and food contamination, being considered of importance for transmission of parasite to the great population contingent. Parasitologic methods have been used to study Crytposporidium oocysts in water and food, although many factors may be involved in processes of histochemical staining, which influence quantitative and qualitative aspects. Parameters as quantification, morphology, quality and time of smears, influence of samples and concentration of substances, were evaluated to observed the value of the Ziehl-Neelsen and Koster attaining modified technique for identification and recovery of Cryptosporidium oocysts in water and food samples, previously concentrated with sacarose, $\mathrm{NaCl}, \mathrm{MgSO}_{4}$, $\mathrm{ZnSO}_{4}, \mathrm{AlSO}_{4}, \mathrm{NH}_{4} \mathrm{SO}_{4}(40 \%$ and $80 \%)$. Statistic differences were not observed between techniques in relation to number of oocysts, although it was visualized variation in the superiority of the technique following the analyzed samples, with quantitative difference. The methods showed no difference in time of smears. The use of $\mathrm{NH}_{4} \mathrm{SO}_{4}$ promotes easier identification of oocysts and AISO4 interfered in the attaining process. The efficiency of hystochemical techniques for Cryptosporidium spp. oocyst identification and recovery depends on the sample nature and substances used for concentration intensity.
\end{abstract}

Keywords: Cryptosporidium spp., Ziehl-Neelsen, Koster, water, milk.

\footnotetext{
* Dept $^{\circ}$ de Nutrição/Centro de Ciências da Saúde da UFPE. Estrada do Encanamento - 350, BL A, Apt ${ }^{\circ}$ 104, Parnamirim, Recife/PE. CEP 52640210. Email: erilane@ig.com.br

** PPGCV / UFRPE

*** UFRPE

**** Dept $^{\circ}$ de Medicina Veterinária da UFRPE

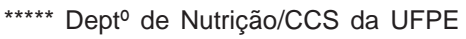




\section{Introdução}

Cryptosporidium spp. é considerado um parasito cosmopolita de caráter zoonótico (Fayer e Unger, 1986). Dentre as espécies que infectam mamíferos, $C$. parvum é o agente responsável pelos casos em humanos (Laberge et al., 1996a), sendo detectado principalmente em crianças e pacientes imunodeprimidos. Newman et al. (1999) identificaram 7,4\% de crianças com criptosporidiose, dentre 189 estudadas com idade média de 543 dias no Nordeste do Brasil. Nos países em desenvolvimento observa-se uma freqüência de $20 \%$ a $30 \%$ em pacientes com imunodeficiência adquirida (AIDS) segundo Petersen (1993). Em alimentos, tem sido encontrado em moluscos - Freire-Santos et al. (2000), em vegetais $(2,5 \%$ a $8,7 \%)$ - Monge e Arias (1996) e em água (87\%) LeChevallier et al. (1991).

Devido à ausência de técnicas específicas comprovadas para a detecção de Cryptosporidium spp. em alimentos, é necessário realizá-las por adaptação da metodologia empregada para análises clínicas. Segundo Laberge et al. (1996), os oocistos de Cryptosporidium spp. podem ser visualizados em amostras fecais por contraste de fase em microscópio eletrônico ou pela utilização de diferentes corantes histoquímicos como o Giemsa, Ziehl-Neelsen, Kinyoun, safranina - azul de metileno (S-AM) e dimetil sulfóxido com microscopia óptica, e por safranina - verde malaquita (Koster modificado) conforme Kagerauka et al. (1984). Podem ser utilizados também os corantes fluorescentes como auraminarodamina, auramina - carbolfuccina (Laberge et al. (1996a) e auramina - fenol (Taylor e Webster, 1998).

Outras técnicas têm sido descritas para a detecção de Cryptosporidium spp., incluindo imunofluorescência direta ou indireta com anticorpos poli ou monoclonais e a reação de polimerase em amostras fecais (Webster et al., 1996), água (Kaucner e Stinear, 1998) e alimentos (Robertson e Gjerde, 2000; Freire-Santos et al., 2000; Laberge et al., 1996b; Deng e Cliver, 2000), além do método imunoenzimático (ELISA) em amostras fecais (Smith, 1993) e citometria de fluxo (FACS) (Vesey et al., 1993b) em amostras de água.

Objetivou-se com este estudo avaliar a eficácia de diferentes técnicas de coloração histoquímica na identificação e recuperação de oocistos de Cryptosporidium spp. em amostras de água e leite.

\section{Material e métodos}

\section{Amostra}

No ensaio experimental foram utilizadas amostras de água de abastecimento público coletadas no momento da análise e leite tipo "C" pasteurizado ( $3 \%$ de gordura) adquiridas no comércio em embalagem de 1 litro, dentro do seu prazo de validade e no mesmo dia da análise.

\section{Inóculo}

Para a contaminação das amostras (100 ml) foi utilizado um inóculo de oocistos de Cryptosporidium spp. não purificado (LeChevallier et al., 1995), extraído de uma suspensão fecal com prévio diagnóstico para o parasito e conservada com formol 10\% por 30 dias em temperatura ambiente. O número médio de oocistos foi determinado antes da inoculação das amostras, e a partir de três repetições, segundo técnica de Kaucner e Stinear (1998). Foram analisadas alíquotas de 0,5 $\mu \mathrm{l}$ direto da suspensão (LeChevallier et al., 1995) através de esfregaço em lâmina e coloração histoquímica pelo método Ziehl-Neelsen modificado (Luna, 1968), sendo a contagem realizada em microscopia óptica com objetiva de imersão (40X) percorrendo-se todo o campo (Oliveira e Germano, 1992).

\section{Procedimento}

Após a inoculação das amostras com 1,2 x 107 oocistos de Cryptosporidium spp. procedeu-se a sua homogeneização e distribuição para tubos de centrífuga na quantidade de $5 \mathrm{ml}$ e, em seguida, submetidas a processos de centrifugação a 206 $\mathrm{G}$ (rotor pendular, temperatura ambiente) por 10 minutos (Deng e Cliver, 1999) em duas etapas para a concentração e reconcentração da amostra seguindo duas distintas metodologias. Ambos métodos foram empregados a partir da mesma amostra contaminada para a comparação entre eles na recuperação de oocistos. Para facilitar a identificação, as técnicas, sugeridas por Webster et al. (1996) e Kageruka et al. (1984) foram denominadas de I e II, respectivamente, e diferiram com relação a ordem de adição da substância de concentração para a mistura com a amostra, na primeira (método I) ou na segunda etapa (método II).

No procedimento com a água no método I realizou-se uma primeira centrifugação colocando nos tubos de centrífuga $5 \mathrm{ml}$ da amostra sob $5 \mathrm{ml}$ de cada solução de concentração denominadas de $A$ (sacarose com densidade igual a 1,065, 32g/ $100 \mathrm{ml}$ ), B (cloreto de sódio com densidade igual a 1,155, $40 \mathrm{~g} / 100 \mathrm{ml}$ ), C (sulfato de magnésio com densidade igual a $1,300,75 \mathrm{~g} / 100 \mathrm{ml}$ ), D (sulfato de zinco com densidade igual a $1,200,40 \mathrm{~g} / 100 \mathrm{ml}$ ) e $\mathrm{E}$ (sulfato de alumínio com densidade igual a $1,115,30 \mathrm{~g} / 100 \mathrm{ml}$ ), além das soluções $\mathrm{F}$ e $\mathrm{G}$ (sulfato de amônia nas concentrações de $40 \%$ p.v. com densidade igual a 1,115 e $80 \%$ p.v. com densidade igual a 1,200 , respectivamente). A partir da primeira centrifugação, outras duas foram realizadas utilizando-se o sobrenadante (SN) e o sedimento (SD) resultantes, ajustando-os para o volume de $2 \mathrm{ml}$ e ressuspendendo-os em $8 \mathrm{ml}$ de água destilada.

Para a amostra de leite o procedimento foi semelhante, mas devido a coagulação do leite após a sua mistura com as soluções de sulfato (C, D, E, F e G) na primeira centrifugação e com o coágulo ocupando a camada intermediária do tubo, foi necessário transferir o sedimento $(2 \mathrm{ml})$ para outro tubo com auxílio de pipeta de $5 \mathrm{ml}$ para ser centrifugado novamente antes de ser analisado. Apesar da mistura do leite com as soluções A e B não resultar em formação de coágulo, o procedimento foi realizado da mesma forma. O coágulo resultante foi lavado com um volume de $10 \mathrm{ml}$ de água destilada e transferido para um recipiente, onde foi dissolvido, sendo depois tamizado, vertido a um tubo de centrífuga e submetido a centrifugação.

No método II foi usado o mesmo procedimento para as amostras de água e leite. Na primeira etapa centrifugou-se $5 \mathrm{ml}$ da amostra colocando-a sobre água destilada em igual volume, enquanto na segunda misturou-se o sedimento $(2 \mathrm{ml})$ resultante da primeira centrifugação, com $8 \mathrm{ml}$ das soluções de concentração supracitadas de $\mathrm{A}$ à $\mathrm{G}$, após descarte do SN com pipeta de Pasteur. 
Após cada centrifugação, com exceção da primeira etapa do método II, os esfregaços foram confeccionados com um volume de $5 \mu \mathrm{l}$ do SN e do SD, e em duplicata para aplicação de dois métodos de coloração.

\section{Codificação}

A codificação feita ao método I refere-se ao tipo de fase resultante da primeira centrifugação (I1), que foi utilizada para a reconcentração da amostra. Nas amostras de água a reconcentração foi procedida a partir das fases sobrenadante e sedimento, denominadas de 12 e 13 , respectivamente. Nas amostras de leite a reconcentração foi realizada também a partir da fase intermediária coagulada denominada de 14, o que ocorreu apenas quando as substâncias C, D, E, F e G foram utilizadas.

\section{Coloração e contagem}

Para a coloração dos esfregaços foram utilizadas as técnicas de Ziehl-Neelsen (Luna, 1968) modificada pelo uso da fuccina fenolada segundo o método Kinyoun (Brasil, 1996) e a técnica de Koster modificada (Kageruka et al., 1984). O Método de Ziehl-Nielsen modificado foi realizado fixando-se o esfregaço rapidamente em bico de Bunsen, seguido pela coloração com a fuccina fenolada (Fuccina Básica PA-4g, Fenol PA-8g, Álcool absoluto PA-20ml, Água destilada-100ml) por 3-5 minutos, cujo excesso foi retirado com água corrente por 10 segundos. Em seguida a descoloração foi feita com solução álcool-ácida e enxágüe imediato em água corrente. Logo após realizou-se a coloração de contraste com a solução de trabalho de azul de metileno $(10 \mathrm{ml}$ de Solução estoque $(1,4 \mathrm{~g} / 100 \mathrm{ml}$ álcool 95\%)/Água destilada q.s.p. 100ml) por 30 segundos a 1 minuto seguida de enxágüe em água corrente por 10 se- gundos e inclinação da lâmina para secagem à temperatura ambiente.

No método de Koster modificado fixou-se o esfregaço em metanol, mergulhando a lâmina no álcool por 1 minuto e em seguida o repouso por 3-5 minutos. Posteriormente a coloração foi feita com solução de safranina (2:5 - safranina saturada / $\mathrm{KOH} 5,6 \%$ ) por 3-5 minutos, sendo seguida de enxágüe em água corrente por 10 segundos. Para a coloração de contraste foi utilizado o verde malaquita $5 \%$ por 15 segundos com posterior enxágüe em água corrente por 10 segundos. Logo após, a lâmina foi inclinada para secagem à temperatura ambiente.

A leitura dos esfregaços e a contagem dos oocistos foi realizada conforme Oliveira e Germano (1992). O número total de oocistos na amostra e o porcentual recuperados foram calculados por equações citadas em Oliveira e Germano (1992) e Deng e Cliver (1999), respectivamente: [(oocistos contados no campo x volume da amostra / volume analisado) / oocistos inoculados] $\times 100$.

\section{Análise estatística}

Para a análise dos resultados foi empregada a ANOVA (análise de variância) com transformação dos dados por RAIZ (X + 1) e a partir de três repetições.

\section{Resultados}

Entre as técnicas de coloração empregadas não foi verificada uma diferença estatística $(p<0,05)$ significativa nas amostras de água e leite, porém diferenças foram observadas quanto a superioridade da técnica de acordo com a amostra analisada (Tabela 1).

Tabela 1 - Comparação entre as técnicas de coloração Ziehl-Neelsen e Koster modificados na identificação de oocistos de Cryptosporidium spp. em amostras de água e leite

\begin{tabular}{|c|c|c|c|c|c|c|}
\hline \multirow{4}{*}{ PARÂMETROS } & \multicolumn{6}{|c|}{ AMOSTRAS } \\
\hline & \multicolumn{3}{|c|}{ ÁGUA } & \multicolumn{3}{|c|}{ LEITE } \\
\hline & \multirow{2}{*}{ Esfregaços } & \multicolumn{2}{|c|}{$\begin{array}{l}\text { Método de } \\
\text { coloração }\end{array}$} & \multirow{2}{*}{ Esfregaços } & \multicolumn{2}{|c|}{$\begin{array}{l}\text { Método de } \\
\text { coloração }\end{array}$} \\
\hline & & ZN & $\mathrm{K}$ & & ZN & K \\
\hline \multirow{2}{*}{$\begin{array}{l}\text { Total de esfregaços corados } \\
\text { Total de esfregaços positivos para a presença } \\
\text { do parasito } \\
\text { Número de esfregaços positivos, equivalentes }\end{array}$} & 168 & 84 & 84 & 198 & 99 & 99 \\
\hline & 100 & 49 & 51 & 74 & 32 & 42 \\
\hline $\begin{array}{l}\text { Número de esfregaços positivos, equivalentes } \\
\text { em pares de amostras, quando corados por } \\
\text { ambas as técnicas }\end{array}$ & 86 & 43 & 43 & 48 & 24 & 24 \\
\hline $\begin{array}{l}\text { Número de esfregaços positivos, quando } \\
\text { corados por uma das técnicas }\end{array}$ & 12 & 5 & 7 & 26 & 8 & 18 \\
\hline
\end{tabular}

Nas amostras de água, em 59,5\% (100/168) dos esfregaços o parasito foi detectado, salientando-se que havia 84 esfregaços corados por cada técnica. Nos 86 esfregaços em pares de amostras, a positividade ocorreu em 43 esfregaços para as técnicas Ziehl-Neelsen (ZN) e Koster (K) e em 12 esfregaços cinco foram positivos quando corados apenas pela técnica ZN e sete pela técnica K. Quanto ao número de oocistos presentes, dos 43 esfregaços referentes a cada técnica, a técnica ZN foi superior em 30 esfregaços à técnica $\mathrm{K}$, totalizando uma superioridade em 35 esfregaços. A maior superioridade da técnica ZN sobre a técnica K ocorreu para qualquer das substâncias utilizadas para concentrar a amostra, com exceção da sacarose.

Nas amostras de leite 37,4\% (74/198) dos esfregaços apresentaram o parasito, salientando-se que havia 99 esfregaços corados por cada técnica. Nos 48 esfregaços em pares de amostras, a positividade ocorreu em 24 esfregaços para as técnicas de $\mathrm{ZN}$ e $\mathrm{K}$ e em 26 esfregaços oito foram positivos 
quando corados apenas pela técnica $Z N$ e 18 pela técnica $K$. Dos 24 esfregaços, referentes a cada técnica, a $\mathrm{K}$ foi superior em 10 esfregaços à técnica ZN, quanto ao número de oocistos presentes, totalizando uma superioridade em 28 esfregaços. $\mathrm{A}$ maior superioridade da técnica $\mathrm{K}$ sobre a $\mathrm{ZN}$ ocorreu para qualquer das substâncias utilizadas para concentrar a amostra, com exceção do cloreto de sódio e do sulfato de amônia $40 \%$.

Os esfregaços realizados foram resultantes da análise do sedimento concentrado a partir das substâncias Sacarose, $\mathrm{NaCl}, \mathrm{MgSO}_{4}, \mathrm{ZnSO}_{4}, \mathrm{AlSO}_{4}, \mathrm{NH}_{4} \mathrm{SO}_{4} 40 \%$ e $80 \%$ e por cada método de análise I1, I2, I3 e II nas amostras de água e leite, e no 14 apenas nas amostras de leite, realizados em três repetições. Diante dos melhores resultados para cada amostra analisada, o método ZN possibilitou a determinação de oocistos de Cryptosporidium em uma recuperação de 13,2\% nas amostras de água com o $\mathrm{NaCl}$ no método I3, enquanto o método $\mathrm{K}$ determinou os oocistos em uma recuperação de $53,5 \%$ nas amostras de leite com o $\mathrm{MgSO}_{4}$ no método 14 .

\section{Discussão}

Observou-se durabilidade dos esfregaços com a utilização dos métodos de coloração histoquímica, pois o período de leitura e contagem variou de 1 a 8 dias após o procedimento de coloração.

Amato Neto et al. (1996) comentam que nos processos histoquímicos para coloração dos oocistos de Cryptosporidium spp., o procedimento de descoloração e lavagem em água corrente influencia na quantificação do número de oocistos devido ao desprendimento de parte do esfregaço. Também relatam que a durabilidade do esfregaço é atributo deste método de identificação, capaz de favorecer a natureza de tarefas específicas e possibilitar exame de diversas lâminas, aumentando assim a sensibilidade.

Baxby et al. (1984) citam que dentre as estruturas presentes em material analisado para pesquisa de Cryptosporidium spp. em amostras fecais, podem ser evidenciados esporos de bactérias, leveduras e restos fecais, sendo que os dois últimos interferem no diagnóstico.

No método ZN e Koster modificado (K) observou-se a ocorrência de artefatos de tamanho e forma semelhantes ao oocisto de Cryptosporidium spp., mas diferentes quanto à cor. Pesquisas mostram que é comum confundir o oocisto de Cryptosporidium spp. com restos fecais, tanto no método ZN (Smith et al., 1989) como no método K (Amato Neto et al., 1996), sendo essencial a presença de um técnico suficientemente habilitado, principalmente pela ocorrência de oocistos "fantasmas" não corados (Amato Neto et al., 1996).

Concordando com Kageruka et al. (1984), no presente estudo verificou-se a eficácia dos métodos de coloração para a identificação do Cryptosporidium spp., que foi confirmada pela facilidade de distinção entre o oocisto e leveduras ou artefatos em ambos métodos, Koster e Ziehl-Neelsen modificados, quando no método de Giemsa não é sempre fácil segundo o autor (Kageruka et al., 1984). Semelhante às observações de Kageruka et al. (1984), a vantagem do método $\mathrm{K}$ em relação ao ZN deve-se à melhor diferenciação dos detaIhes das estruturas internas.

Neste estudo foram considerados os oocistos vazios e com estruturas internas (Figura 1) conforme Bennett et al. (1999), e de coloração com graus de rosa tanto no método ZN como no método K. Ainda foram identificados os oocistos de forma circular ou ocasionalmente oval (Figura 1) conforme Pohjola (1984), ou irregular de acordo com Ongerth e Stibbs (1987), os quais acrescentam que os oocistos de Cryptosporidium spp. podem ser dentados, na forma excistada, com fissuras, na forma de fatia de torta, ou estreitos parecendo uma forma enrugada.

Os oocistos se apresentaram com paredes altamente refráteis igualmente à descrição de Pohjola (1984), principalmente após aplicação do método ZN para coloração. Freqüentemente os oocistos mostraram tendência a aglomerações (Bennett et al., 1999) como apresentado na Figura 1.
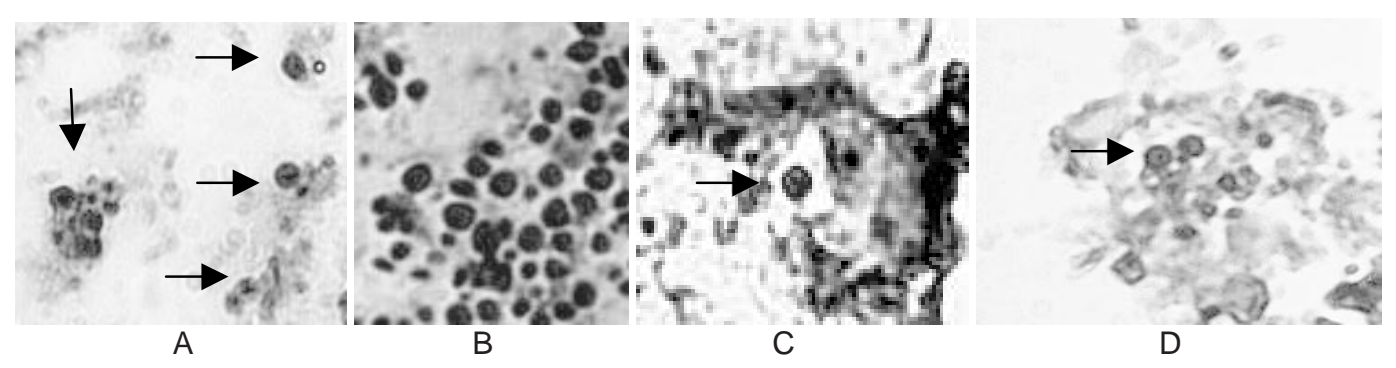

Figura 1: Oocistos de Cryptosporidium spp. corados pelo método Ziehl-Neelsen (A e B) e Koster (C e D) modificados, na ampliação de 1.000 vezes. $1 \mathrm{~A}$. oocistos com conteúdo interno e 1B. oocistos sem conteúdo, aglomerados com formas diferentes nas amostras de água e leite, respectivamente; 1C e 1D. oocistos com conteúdo interno nas amostras de água e leite, respectivamente.

Dentro da mesma técnica de coloração observou-se um grau de variação na cor do oocisto, e isto provavelmente ocorreu devido à presença de precursores dos oocistos (Henriksen e Pohlenz, 1981). Nitidamente verificou-se que após a concentração das amostras de água e leite pela solução de $\mathrm{NH}_{4} \mathrm{SO}_{4}$, a cor do oocisto e do campo de contraste foram intensificadas, enquanto o $\mathrm{AISO}_{4}$ prejudicou intensamente a coloração.
A utilização do método de identificação por coloração histoquímica mostrou ser adequado para o tipo de estudo realizado, pois, segundo Bennett et al. (1999), técnicas de microscopia não são efetivas quando poucos organismos estão presentes na área de contagem. Em câmaras de Neubauer ou em hemacitômetros, o número pode ser alterado devido à evaporação do líquido após 1 hora de contagem. 
A desvantagem dos métodos de citometria de fluxo e contagem em aparelhos automáticos deve-se ao fato da possibilidade de se considerar vários organismos como apenas um.

Em relação às amostras estudadas, foi verificado que os oocistos foram mais bem visualizados e o campo de contraste mais nítido quando pesquisados nas amostras de água, facilitando e conferindo menor tempo de leitura enquanto que, analisando as amostras de leite, o tempo de leitura atingiu seis horas no esfregaço com maior número de oocistos contados. Ongerth e Stibbs (1987) comentam que o tempo do exame microscópico com imunofluorescência indireta sobre uma membrana de $25 \mathrm{~mm}$ e com ampliação de 250 vezes foi avaliado em seis horas (15 a 20 segundos por campo) ou mais quando aumentava o número de partículas estranhas, pois o tamanho do oocisto com 3 a $5 \mathrm{~mm}$ não permite o uso de uma menor ampliação.

Os métodos de coloração com relação às amostras de água mostraram menor facilidade à descoloração, resultando em uma coloração intensa, de forma que o esfregaço pôde ser nitidamente visualizado com a ampliação de 400X, enquanto nas amostras de leite a observação com a ampliação de 1.000X foi necessária para confirmar a identificação do oocisto na maioria das leituras dos esfregaços.

Quanto aos corantes de contraste, foi possível determinar que o verde malaquita desempenhou melhor a função, permitindo nitidez do campo e favorecendo o melhor contraste com os oocistos (Figura 1).

\section{Conclusão}

Conclui-se que, no processo de coloração dos oocistos, ocorre influência das amostras e das substâncias de concentração utilizadas no procedimento, de forma que a cor pode ser intensificada com o uso de sulfato de amônia, e que os métodos de coloração histoquímica não influenciam quantitativamente, mas qualitativamente na recuperação dos oocistos.

\section{Agradecimentos}

Os autores agradecem à Márcia Pascoal de Lima (Lab. de Paras. da UFPE) pelo treinamento no diagnóstico laboratorial, à Patrícia Valadares Gusmão e a Laurineide L. C. Freire (Lab. Central da FUSAM), ao Prof. Frederico Celso Lira Maia e aos colegas do Lab. de Doenças Paras. da UFRPE pelo apoio, à Profa Isabele M. J. Meunier pela análise estatística e ao CNPq pela bolsa concedida.

\section{Referências}

AMATO NETO, V., BRAZ, L. M. A., PIETRO, A. O. D., MÓDOLO, J. R. Pesquisa de oocistos de Cryptosporidium sp. em fezes: comparação entre os métodos de Kinyoun modificado e de Heine. Revista da Sociedade Brasileira de Medicina Tropical, v. 29, n. 6, p. 575-578, nov.dez. 1996.

BAXBY, D., BLUNDELL, N., HART, C. A. The development and performance of a simple, sensitive method for the detection of Cryptosporidium oocysts in faeces. Journal of Hygiene, Cambridge, v. 92, p. 317-323, 1984.

BENNET, J. W., GAUCI, M. R., MOËNIC, S. L., SCHAEFER III, F. W., LINDQUIST, H. D. A. A comparison of enumeration techniques for Cryptosporidium parvum oocysts. Journal of Parasitology, v. 85, n. 6, p. 1165-1168, 1999.

BRASIL. MINISTÉRIO DA SAÚDE. Infecções oportunistas por parasitas em AIDS: técnicas de diagnóstico. Brasília, DF. 1996. 27 p.

DENG, M. Q., CLIVER, D. O. Cryptosporidium parvum studies with dairy products. International Journal of Food Microbiology, v. 46, p. 113-121, 1999.

DENG, M. Q., CLIVER, D. O. Comparative detection of Cryptosporidium parvum from apple juice. International Journal of Food Microbiology, v. 54, p. 155-162, 2000.

FAYER, R., UNGER, B.L.P. Cryptosporidium spp. and Cryptosporidiosis. Microbiology Review, v. 50, p. 458-483, 1986.

FREIRE-SANTOS, F., LOPEZ, A. M. O., CASTIBLANCO, C. A. V., MAZÁS, E. A., SUÁREZ, E. A., MARTíN, O. G. Detection of cryptosporidium oocysts in bivalve mollusks destined for human consumption. Journal of Parasitology, v. 86, n. 4, p. 853-854, 2000.

HENRICKSEN, S. A., POHLENZ, J. F. L. Staining of Cryptosporidia by a modified Ziehl-Neelsen technique. Acta Veterinaria Scandinavica, v. 22, p. 594-596, 1981.

KAGERUKA, P., BRANDT, J. R. A., TAELMAN, H., JONAS, C. Modified Koster staining method for the diagnosis of cryptosporidiosis. American society belge of Medicine Tropical, v. 64, p. 171-175, 1984.
KAUCNER, C., STINEAR, T. Sensivite and rapid detection of Giardia cysts and Cryptosporidium parvum oocysts in large - volume water samples with wound fiberglass cartridge filters and reverse transcription - PCR. Applied and Environmental Microbiology, USA, v. 64, n. 5, p. 1743-1749, May, 1998.

LABERGE, I., GRIFFITHS, M. W., GRIFFITHS, M. W. Prevalence, deteccion and control of cryptosporidium parvum in food. Int. Journal of Food Microbiology, v. 31, p. 1-26, 1996a.

LABERGE, I., IBRAHIM, A., BARTA, J. R., GRIFFITHS, M. W. Detection of Cryptosporidium parvum in raw milk by PCR and oligonucleotide probe hybridization. Applied and Environmental Microbiology, USA, v. 62, n. 9, p. 3259-3264, 1996b.

LeCHEVALLIER, M. W., NORTON, W. D., Lee, L. G. Ocurrence of Giardia and Cryptosporidium spp. in surface water supplies. Applied and Environmental Microbiology, USA, v. 57, n. 9, p. 2610-1616, Sept. 1991.

LeCHEVALLIER, M. W., NORTON, W. D., SIEGEL, J. E., ABBASZADEGAN, M. Evaluation of the immunofluorescence procedure for detection of Giardia cysts and Cryptosporidium oocysts in water. Applied and Environmental Microbiology, USA, v. 61, n. 2, p. 690-697, Feb. 1995.

LUNA, L. G. Manual of Histologic staining methods of the Armed Forces Institute of Pathology. 3. ed. McGraw Hill Book Company, 1968, $258 \mathrm{p}$.

MEDEMA, G. J., SCHETS, F. M., TEUNIS, P. F. M., HAVELAAR, H. Sedimentation of free and attached Cryptosporidium oocysts and Giardia cysts in water. Applied and Environmental Microbiology, USA, v. 64, n. 11, p. 4460-4466. Nov. 1998.

MONGE, L., ARIAS, M. L. Presencia de microorganismos patógenos en hortalizas de consumo crudo en Costa Rica. Archivos Latinoamericanos de Nutrición, v. 46, n. 4, p. 292-294, 1996.

NEWMANR. D., SEARS, C. L., MOORE, S. R., NATARO, J. P., WUHIB, T., AGNEW, D. A., GUERRANT, R. L., LIMA, A. A. M. Longitudinal study of infection in children Northeastern Brazil. The Journal of Infectious Diseases, v. 180, p. 167-175, 1999. 
OLIVEIRA, C. A. F., GERMANO, P. M. L. Estudo da ocorrência de enteroparasitas em hortaliças comercializadas na região metropolitana de São Paulo - SP, Brasil - I / Pesquisa de helmintos. In: OLIVEIRA, C.A.F., GERMANO, P.M.L. Estudo da ocorrência de enteroparasitas em hortaliças comercializadas na região metropolitana de São Paulo - SP Brasil - II / Pesquisa de protozoários intestinais. Revista de Saúde Pública, São Paulo, SP, v. 26, n. 5, p. 332-335, 1992.

ONGERTH, J. E., STIBBS, H. H. Identification of Cryptosporidium oocysts in river water. Applied and Environmental Microbiology, USA, v. 53, n. 4, p. 672-676, Apr., 1987.

PETERSEN, C. Cellular biology of Cryptosporidium parvum. Parasitology Today, v. 9, p. 87-91, 1993.

POHJOLA, S. Negative staining method with nigrosin for the detection of cryptosporidial oocysts: a comparative study. Research in Veterinary Science, v. 36, p. 217-219, 1984.

ROBERTSON, L. J., GERDE, B. Isolation and enumeration of giardia cysts, Cryptosporidium oocysts, and Ascaris Eggs from fruits and Vegetables. Journal of Food Protection, USA, v. 63, n. 6, p. 775-778, 2000.
SMITH, H. V., McDIARMID, A., SMITH, A. L., HINSON, AR, GILMOUR, RA An anlysis of staining methods for the detection of Cryptosporidium spp. Oocysts in water-related samples. Parasitology, v. 99, p. 323327, 1989.

SMITH, J. L. Cryptosporidium and Giardia as Agents of Foodborne Disease. Journal of Food Protection, v. 56, n. 5, p. 451-461, 1993.

TAYLOR, M. A., WEBSTER, K. A. Recent advances in the diagnosis in livestock of Cryptosporidium, Toxoplasma, Giardia and other protozoa of veterinary importance. Research in veterinary Science, v. 65, p. 183-193, 1998.

WEBSTER, K. A., SMITH, H. V., GILES, M., DAWSON, L., ROBERTSON, L. J. Detection of Cryptosporidium parvum oocists in faeces: comparison of conventional coproscopical methods and the polymerase chain reaction. Veterinary Parasitology, v. 61, p. 5-13, 1996.

VESEY, G., SLADE, J. S., BYRNE, M., SHEPHERD, K., DENNIS, P. J., FRICKER, C. R. Routine monitoring of Cryptospporidium oocysts in water using flow citometry. Journal of Apllied Bacteriology, v. 75, p. 87-90, 1993b. 